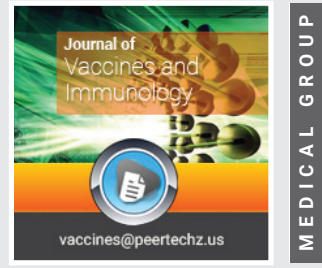

\title{
Saliva as a source of antibodies for MMR vaccine screening in
}

\section{teenagers}

\author{
Barbara Fialho Carvalho Sampaio ${ }^{1,2 *}$, Luciana Regina \\ Meireles ${ }^{1}$ and Heitor Franco de Andrade ${ }^{1,2}$ \\ ${ }^{1}$ Laboratory of Protozoology, Institute of Tropical Medicine of São Paulo, University of Sao Paulo, \\ Brazil \\ ${ }^{2}$ Pathology Department, School of Medicine, University of Sao Paulo, Brazil
}

Received: 15 May, 2021

Accepted: 22 May, 2021

Published: 24 May, 2021

*Corresponding author: Barbara Fialho Carvalho Sampaio, M.Sc, PhD, Laboratory of Protozoology, Institute of Tropical Medicine of São Paulo, University of Sao Paulo, Av. Dr. Eneas de Carvalho Aguiar, 470, $1^{\circ}$. andar, 05403-000, São Paulo, SP. Brazil,

E-mail: bcarvalho@usp.br

Keywords: Antibodies; Measles; Rubella; Mumps; Saliva

https://www.peertechzpublications.com

\section{Check for updates}

\begin{abstract}
The use of safe and effective vaccines is a well-established public health intervention, with a major impact on the fall in the prevalence of infectious diseases. In the absence of environmental transmission, vaccines do not work for life, as originally detected. This has now generated the occurrence of vaccinated susceptible people, which allows the importation of diseases, since vaccination coverage does not equate to population immunity. The serological control of the vaccination status and the protection of a population is essential, and its execution is not friendly due to the blood collection necessary for the tests. In these assays, the specific IgG for the vaccine agent is quantified, it would be important to detect IgA as well. This is an immunoglobulin secreted for mucous membranes that neutralizes or directs the agent to nonpermissive neutrophils, it is very important in vaccine protection, but difficult to detect and quantify. Saliva can be a friendly alternative material as a source of IgA and IgG for use in conventional tests and its obtainment is not invasive, facilitating the acceptance of these studies in protected groups. We standardized assays with detection of antibodies in solid phase, to prospect for effective vaccine coverage in adolescents using saliva as a biological fluid. Once established and standardized, these techniques will allow for eventual vaccine control without the need for aversive blood collection, adequate public health measures, such as revaccination, can be adequately planned.
\end{abstract}

\section{Introduction}

The use of safe and effective vaccines is a well-established and cost-effective public health intervention in the past three decades and has a major impact on the prevalence of infectious diseases. Each year, vaccines prevent more than three million deaths, consolidating success in preventing infectious diseases each year [1].

According to the State of the World's Vaccines and Immunization report [2], "Vaccination - even with the addition of new, more expensive vaccines - remains one of the most cost-effective health interventions". The publication notes that more children are reached with the immunization of one hundred million children per year in the period 20052007, approximately. And the benefits of immunization are increasingly extended to adolescents and adults, providing protection against potentially fatal diseases, such as influenza, meningitis and cancers that occur in adulthood [3].
Despite this progress, vaccine-preventable diseases continue to be a major cause of morbidity and mortality. Adoption of new vaccines by low- and middle-income countries has been slower than in high-income countries.The vision for the "Vaccine Decade (2011-2020)" is of a world where all individuals and communities can enjoy a life free of vaccinepreventable diseases. This mission has the central objective of expanding, until 2020, the full benefit of immunization for all people, regardless of where they are born, live or who they are. This vision of a world without diseases protected by vaccines is a utopia, but even so, we have to try to achieve the unattainable.

Some authors have demonstrated that there may be a lack of response to the vaccine, called primary vaccine failure (FVP), in about $2 \%$ to $5 \%$ for measles, $3 \%$ to $7 \%$ for mumps and $2 \%$ to $5 \%$ for rubella $[4,5]$. Among the main causes of PVF are the presence of maternal antibodies and the improper conditions of the vaccine (handling, administration, cold chain). It has also been shown that secondary vaccine failure (FVS) can occur, which is the drop in antibody levels, which over time 
can reach levels so low or undetectable that they do not provide more protection. These studies have observed that the levels of antibodies after vaccination are lower than after natural infection $[6,7]$.

For these reasons, even with an effective immunization program in a child population, birth and the vaccination period can generate susceptible after a few years; therefore, vaccination coverage may not be equivalent to population immunity [8]. During the past few decades, the triple viral vaccine has been introduced into immunization policy in several countries. In order to have a good immunization, two doses are recommended, the first at 12-15 months of age and the second at 4-6 years of age, in order to cover possible vaccine failures [9]

The vaccination process is the most effective public health intervention in the control of infectious diseases. The detection of the presence of specific IgG antibodies in serum has numerous medical uses, whether in detecting contact with infectious agents, such as in human toxoplasmosis or in demonstrating vaccine efficiency for some diseases such as measles, mumps and rubella.

Normally, serological studies have used blood collection, through classic needle puncture with serum production or whole blood collections using a lancet and on filter paper. The two materials, with different degrees of purity, are sources of specific IgG, detected by tests of different sensitivities and specificities standardizes the amount of IgG captured and allows for the improvement of assays and even possible fluorescent multiplexed assays. In previous trials, we noticed a great resistance from the school community and their families in the process of voluntary blood or saliva collection, remembering that due to the age of the adolescents, parents would have to authorize the collection and, later, students would have to authorize the collection also by the Term of Assent.

In this work, we developed methods of greater efficiency and sensitivity in the detection of specific IgG against various agents, such as measles, mumps and rubella, with adequate standardization and quality control.

The set of these actions will allow non-invasive studies of vaccinated young populations, of lower cost and using techniques from already validated methods, resulting in a study of incidence monitoring and the evaluation of vaccination efficiency by the triple viral vaccine, after ten years of the initial immunization.

\section{Material and methods}

\section{Studied population}

The population of this study was considered children and university students regularly enrolled in the teaching centers of São Paulo, affiliated with our project, in the age group of ten to fourteen years for students of elementary school II and eighteen to twenty years for university students.

Our population consisted of 90 students' saliva, 50 positive samples and 40 negative samples.
The choice of age groups is based on the assumption that everyone is vaccinated and can correlate whether or not there is a decrease in antibody titers over the years.

To control our tests, serum samples from infants between eight and twelve months of age were selected, provided by the Instituto da Criança laboratory - HCFMUSP, which would be discarded by the institute.

Previous visits to the exhibition were held to clarify the project with students, teachers, coordinators, principals, the Midwestern Board of Education and legal guardians of minors. After clarifying the project, the Informed Consent were given to the students for study consent and we left an open channel for clarification with those responsible in case of any doubts regarding the intervention (saliva collection).

All volunteers brought the Informed Consent, containing all the procedures to be developed, according to Resolution GCP-ICH, which regulates research involving human beings. All minor volunteers received the Term of Assent. It is worth mentioning that this study was submitted to the Research Ethics Committee and approved under process No. 23109613.1.0000.0065.

\section{Viral antigens}

Recombinant antigens from measles virus nucleocapsid (Priorix $60 \mathrm{kDa}$ ) of the Schwartz viral strain, the rubella virus capsid ( $35 \mathrm{kDa})$ and the surface protein of the wild type mumps virus of the Gloucester lineage (66 KDa) were obtained from . ABCAM ${ }^{\circledR}$ (Eugene, Mass., USA). All of those antigens were labelled with biotinamido hexanoic acid hydroxysuccinimide according supplier protocol (B2643- Sigma Chem Co. St Louis USA), and purified on BioGel P2 molecular exclusion chromatography on ÄKTA liquid chromatography system. The labelled products had 4- 6 biotin residues added to the protein and were adjusted to $0.1 \mathrm{ug} / \mathrm{ml}$ in phosphate buffered saline $0,02 \mathrm{M} \mathrm{pH} 7.5$ containing Bovine serum albumin $1 \mathrm{mg} / \mathrm{ml}$ and Tween $200.02 \%$ (PBSTA).

High protein binding certified 96 microplates were adsorbed with 1 ug staphylococcal Protein A in carbonate buffer $0.1 \mathrm{M} \mathrm{pH} 9.0$ overnight at $4^{\circ} \mathrm{C}$. Eventual free binding sites were blocked with PBSTA for additional 4 hs incubation. All subsequent steps were followed by 5 washings with PBSTA. IgG containing samples were adequately diluted in PBSTA and reacted to the wells for protein A IgG capture by $1 \mathrm{~h}$ at $37^{\circ} \mathrm{C}$ in humid chamber. The wells were reacted with biotinylated antigen by $1 \mathrm{~h}$ at $37^{\circ} \mathrm{C}$ in humid chamber, and avidin-peroxidase complex (ABC) $0.1 \mathrm{ug} / \mathrm{ml}$ added and incubated by $1 \mathrm{~h}$ at $37^{\circ} \mathrm{C}$ in humid chamber. Finally, peroxidase of bound complex was detected using TMB commercial reagent by $30 \mathrm{~min}$ and the reaction stopped by $\mathrm{HCl} 4 \mathrm{~N}$ addition.

\section{Results}

Protein A capture ELISA was initially standardized with sera previously defined as positive and negative, paired with saliva as demonstrated by Sampaio and collaborators. This immunological technique is based on the fact that the antibodies 
bind to protein A by the Fc portion, previously adsorbed on the solid support, exposing the Fab fractions. After washing, the complex formed by protein A and IgG allows the binding of the antigen it presents biotin and this allows the posterior binding of the avidin-peroxidase complex and development by commercial TMB.

The reaction was carried out as described in Methods with plates adsorbed with $5 \mathrm{ug} / \mathrm{ml}$ of Protein A. Then, the samples were incubated with biotinylated antigen at the concentration defined in the previous section, washed and finally reacted with avidin-peroxidase complex. For the development of the peroxidase bound to the complex on the solid support, we used high sensitivity commercial TMB. We work with intratest controls in all reactions, in which no reaction was presented with the samples. The ELISA reaction captures Protein A for previously known saliva were tested in the same manner as described above.

For measles, as seen in Figure 1, we note a clear discrimination between positive (50) and negative (40) saliva for measles antigen. The sensitivity of the assay was $98 \%$ (95\% CI $89-99 \%$ ) and the specificity was $91 \%$ (95\% CI $79-96 \%$ ) which was excellent, although some false positives (1) and false negatives (4) have occurred.

This fact can be explained by the decrease in memory antibody titers throughout life, as seen in Figure 1.

For the mumps antigen, as we can see in Figure 2, the reactivity of positives was less intense, although with clear discrimination between positives and negatives. Using the cutoff of two standard deviations, there was a greater number of false negatives (10), but without false positives, which resulted in $100 \%$ sensitivity (95\% CI $91-100 \%$ ) and $80 \%$ specificity ( 95 CI \% 67-89\%). This fact is related to a lower intensity of the reaction and perhaps to a less efficient response quantitatively to the vaccine, since the criterion of positivity was that of a young adult with complete childhood vaccination.

For the rubella virus antigen, we can see the result of our assay in Figure 3, in which we note that the populations were again clearly distinguished by the assay, albeit with a greater background of positivity and interbreeding. The negative reactions of vaccinated adults may have been caused by the loss of antibodies produced by a less lasting immunization despite the previous vaccination. The test had a sensitivity of 95\% (I.C. $95 \% 85-99 \%$ ) and a specificity of $83 \%$ (I.C. $95 \% 69-91 \%$ ). The finding of false positives in the fraction of negative pools could be explained by the cross reaction with other viral antigens occurring in this age group.

After proving a sensitivity and specificity for our test using saliva as a biological fluid, for all antigens against the triple viral vaccine, we went to evaluate the efficiency of our Protein A capture assay and development with biotinylated antigens, we carried out reproducibility test, as observed Next. The samples were re-tested at different days and times, using a different avidin-peroxidase preparation. As seen in Figure 4, there is an excellent correlation between the tests with a high correlation.

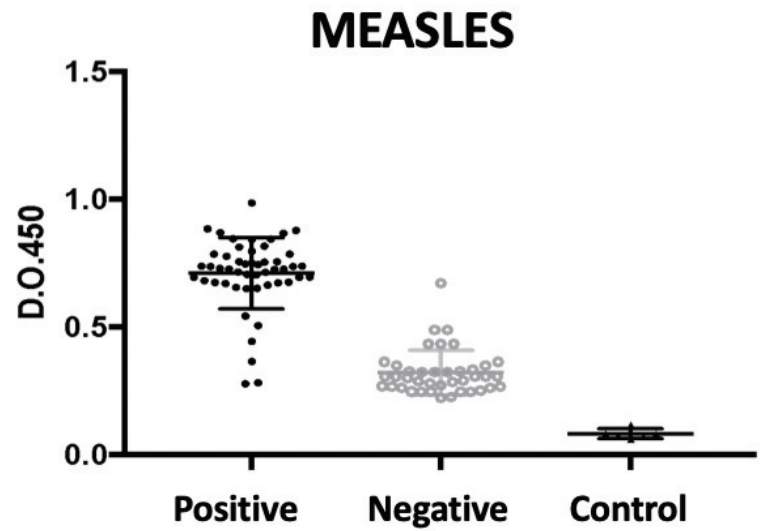

Figure 1: Results of the Protein A - Measles capture ELISA immunoenzymatic test for previously known saliva samples.

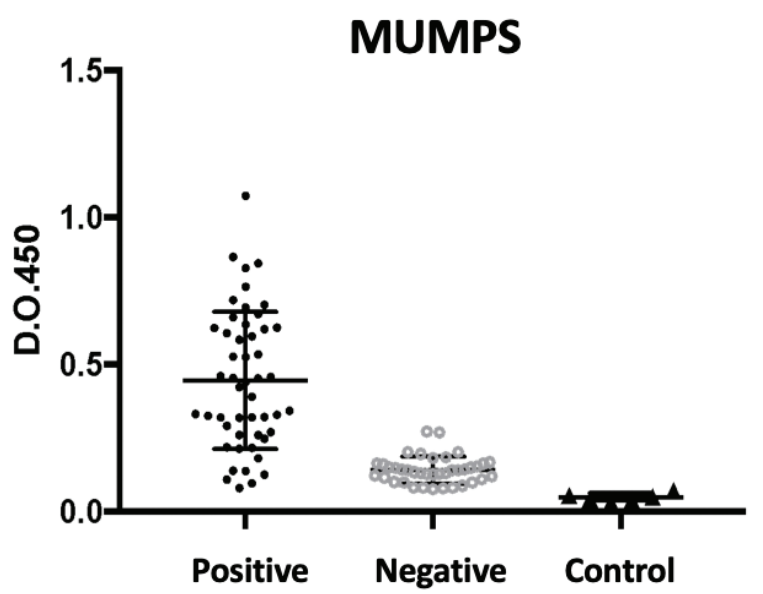

Figure 2: Results of the Protein A - Mumps capture ELISA immunoenzymatic test.

\section{RUBELLA}

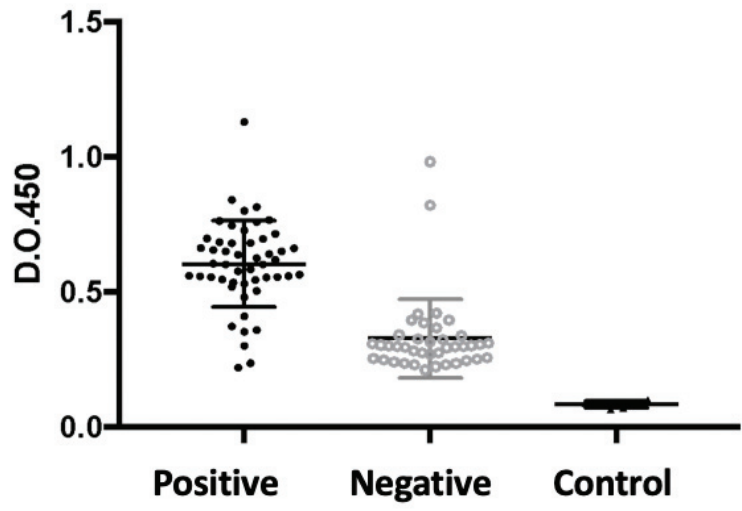

Figure 3: Results of the Protein A - Rubella capture ELISA immunoenzymatic test for previously known serum samples.

\section{Discussion}

A study carried out in Finland showed that antibodies induced by the MMR vaccine decrease significantly after the second dose, according to epidemiological data from the country. The protection induced by this vaccine seems to persist 

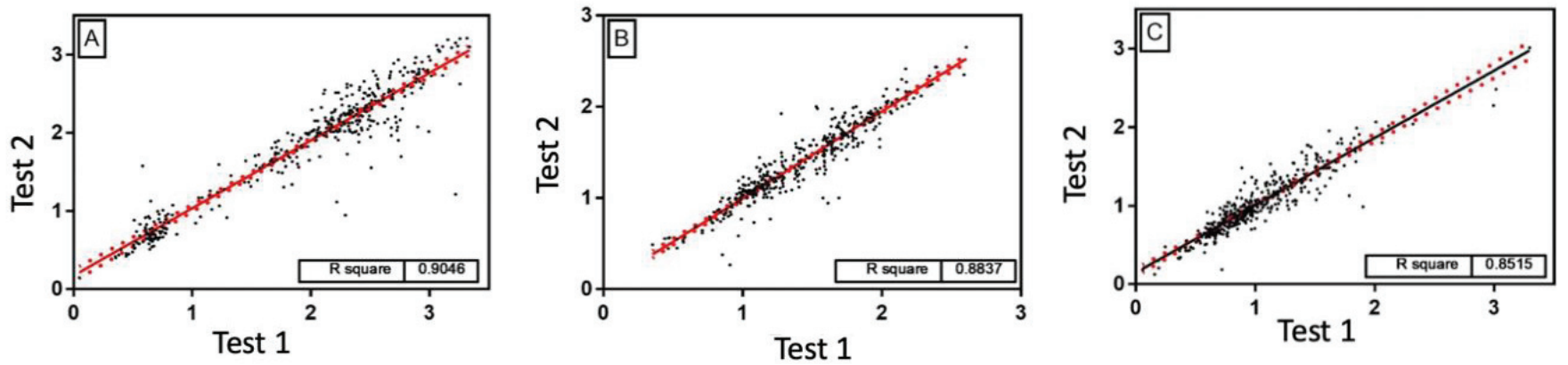

Figure 4: ELISA reproducibility test Capture Protein A for the three antigens studied. Two independent reactions were run at different days and different microplates and reagents, using the same dilution of saliva sample. Antigens: A- Measles, B- Mumps and C- Rubella. Line represents estimated linear regression curve using Pearson correlation, and $\mathrm{r} 2$ and statistical significance are inserted each graph. Broken line represents the $95 \%$ confidence interval of the estimation.

at least until the beginning of adulthood, however the situation requires constant surveillance [10]. There is a progressive drop in the mean serum antibody titers after fifteen years of the second dose of the triple viral vaccine, with a greater drop in positivity in mumps viruses, but significant in the other viruses.

Antibodies against measles, mumps and rubella decrease about 3\% per year, on average, and show a high degree of individual variation. The rate of antibody decay varies substantially between individuals and between the three groups of antigens present in the MMR vaccine, however the rate of decline together with high variation was observed with more proportions for mumps [11].

Prevalence studies of antibodies against measles, mumps and rubella are not only interested in measuring the proportion of the immune population, but provide data that support the new immunization strategies to be introduced to control eventual vaccine failures and predict the occurrence epidemic outbreaks, as they have been frequent in our country.

Thus, developing diagnostic tests that facilitate the surveillance of the vaccine protection of the population is essential for us to avoid possible outbreaks.

Since protein $\mathrm{A}$ has a molecular weight of $41 \mathrm{KDa}$ and binds to the solid substrate through a bond, it allows two IgG molecules to bind to the substrate and expose four FABs. Thus, a 1ong binding of protein A results in a 9ong binding of IgG to the plate, increasing the absorption of the solid support by almost ten times. Several other chemical methods have been used to adhere to IgG directly to solid supports, such as those used in plasmon resonance and other detection methods [12], but the capture proposed in this study provides comparatively more FABs for specific detection, which seems ideal for detection of Specific IgG and does not capture antigens by monoclonal.

Our data was equally efficient and reproducible for all antigens. Initially, the assays were tested with sera, which has an excess of IgG, while the amount of IgG in saliva is much lower [13]. which could interfere with the result. As expected, the IgG reactivity of saliva was very similar to the reactivity of serum IgG, as shown in all of our assays. This result was certainly directly related to the use of Protein A capture in the solid support, which standardized the supply of IgG for reaction with the biotinylated antigen.

There are many references reporting the detection of antibodies in saliva, reviewed by various groups $[14,15]$, but saliva is used in an imprecise way in qualitative tests and not in our quantitative approach, which used the capture of IgG by Protein A.

Saliva was used for the detection of population immunity in the detection of IgG against measles, rubella and hepatitis $\mathrm{C}$ in 2001, but the assay involved the direct reaction of the oral fluid in a commercial ELISA, without the capture of IgG [16], which resulted in great proportion of false negatives, above $50 \%$ for hepatitis C.

The IgG capture approach, in addition to ensuring a uniform amount of IgG, also decreased the risk of competition with other more frequent immunoglobulins in saliva, such as IgA, which could cooperate with false negative results by blocking the IgG reaction in the presence large titers of specific IgA. Antibody competition was mentioned by authors, who worked with dengue serology on various biological materials [17].

Our data showed several important aspects of vaccination by the triple viral virus. Most importantly, measles vaccination coverage in our group is relatively maintained, while rubella and mumps protection is less durable with a significant "susceptible" fraction, which would explain the recent outbreaks of these viruses in our environment, in addition to the need for additional vaccine doses in adolescence, an important sanitary measure for the prevention of congenital rubella [18].

Our data corroborate some reports in the literature of preferential loss of immunity against mumps and rubella, before loss to measles. There are different mumps viruses among vaccines with different degrees of efficiency [19]. The worldwide market for triple viral vaccine is controlled by commercial companies and few quality control work has been carried out. In a recent review, Plotkin comments on several aspects of the concomitant immunogenicity of viral infections preventable by MMR. There is a correlation between antibodies 
and protection against measles and rubella, but few studies have been done with mumps and, even in this review, there are no reports of efficiency tests for this vaccine [20].

Our studies show that there may be a shorter duration of protection against the two less dominant viruses (rubella and mumps) in our population and the explanation is complex for this fact. The measles virus, in a natural infection, induces a great immunosuppression of the host, as assessed by the histology of the lung in children [21]. The measles vaccine appears to affect vaccine immunity, but apparently in the opposite direction, it increases resistance to infections. It is interesting to note that the disappearance of immunity is reported only in two secondary vaccine viruses [22], such as that found in our population.

There are no reports of constant quality control over the commercial preparation of the vaccine and it may be that there may be more environmental resistance from the measles virus, since it was only systematically isolated from the vaccine preparations determined here, in an empirical and anecdotal way. So, it is not unexpected to lose immunity to secondary vaccine viruses, both due to the supremacy of the measles virus and the evident absence of prospective long-term studies, but short-term reports have already demonstrated this problem [23]. The need for prevention of congenital rubella syndrome has been the main concern and obliged to recommend revaccination in adolescence with the triple viral [22], as has been done in our state.

Resurgent outbreaks of vaccine-preventable diseases that have been controlled or eliminated have been observed in many contexts.

Vaccination campaigns can prevent or even control outbreaks, but they must be worked with considerable certainty, since surveillance, in real time, can provide valuable information about the population at risk and what would be the main vaccination targets to block possible outbreaks . However, we run into preventive diagnostic limitations, since the ideal would be to confirm the immune status of each individual, before an unnecessary revaccination [24].

Our approach was efficient in all aspects, from the collection and use of saliva. With this, we were able to develop reliable tests to determine the vaccine protection of students and to prevent possible outbreaks. However, in order to establish this technique as the gold standard for checking vaccinations in children and adolescents, we need to increase the sample number.

It is important to recognize the possibility of recurrent outbreaks and epidemics in this post-elimination phase and / or increased population immunity due to vaccination, with the need to prepare a sensitive surveillance system for a more effective blocking response.

\section{Conclusion}

The use of saliva allowed to determine the prevalence of antibodies against the viruses of the triple viral vaccine in students in the city of São Paulo, however more studies with populations of different age groups and in the long term are of fundamental importance to understand how the immune memory behaves over time in a population with vaccination rates above $90 \%$.

\section{References}

1. Ehreth $\mathrm{J}$ (2003) The value of vaccination:a global prespective. Vaccine 21 : 4105-4117. Link: https://bit.ly/3ucQTxV

2. World Health Organization (2009) UNICEF, World Bank. State of the world's vaccines and immunization. 3rd ed. Geneva: WHO. Link: https://bit.ly/3hNeh2A

3. World Health Organization (2013) Global Vaccine Action Plan 2011 - 2020 Link: https://bit.ly/3hPN7bw

4. St Sauver JL, Jacobson RM, Vierkant RA, Jacobsen SJ, Green EM, et al. (2001) Correlations between measles, mumps, and rubella serum antibody levels in Olmsted County school children. Vaccine 19: 1363-1368. Link: https://bit. ly/3feo4gi

5. Bautista-López N, Ward BJ, Mills E, McCormick D, Martel N, et al. (2000) Development and durability of measles antigen-specific lymphoproliferative response after MMR vaccination. Vaccine 18: 1393-1401. Link: https://bit.ly/3hOATQ

6. Christenson B, Böttiger M (1994) Measles antibody: comparison of long-term vaccination titres, early vaccination titres and naturally acquired immunity to and booster effects on the measles virus. Vaccine 12: 129-133. Link: https://bit.ly/3vszAux

7. Janaszek W, Slusarczyk J (2003) Immunity against measles in populations of women and infants in Poland. Vaccine 21: 2948-2953. Link: https://bit.ly/3bRnD9u

8. Ribas MLA, Tejero Y, Valcarcel M, Galindo M, Cordero Y, et al. (2018) Mumps epidemiology in Cuba between 2004 and 2015. Arch Virol 163: 3059-3064. Link: https://bit.ly/3vjMzyy

9. Plotkin SA, Reef SE, Cooper LZ, Alford Jr CA (2006) Rubella. In: Remington JS, Klein JO, Wilson CB, Nizet V, Maldonado YA, editors. Infectious disease of the fetus and newborn infant. 7 th. Philadelphia: Saunders 861-898.

10. Davidkin I, Jokinen S, Broman M, Leinikki P, Peltola H (2008) Persistence of measles, mumps, and rubella antibodies in an MMR-vaccinated cohort: a 20year follow-up. J Infect Dis 197: 950-956. Link: https://bit.ly/3wyzMsd

11. Seagle EE, Bednarczyk RA, Hill T, Fiebelkorn AP, Hickman CJ, et al. (2018) Measles, mumps, and rubella antibody patterns of persistence and rate of decline following the second dose of the MMR vaccine. Vaccine 36: 818-826. Link: https://bit.ly/2Ryf903

12. Shen M, Rusling J, Dixit CK (2017) Site-selective orientated immobilization of antibodies and conjugates for immunodiagnostics development. Methods 116: 95-111. Link: https://bit.ly/3hVDR5o

13. Sampaio BFC, Macre MS, Meireles LR, Andrade Jr HF (2014) Saliva as a source of anti-Toxoplasma gondii IgG for enzyme immunoassay in human samples. Clin Microbiol Infect 20: 72-74. Link: https://bit.ly/3ufE463

14. Hassaneen M, Maron JL (2017) Salivary diagnostics in pediatrics: applicability, translatability, and limitations. Front Public Health 5: 83. Link: https://bit.ly/3fesvb5

15. Javaid MA, Ahmed AS, Durand R, Tran SD (2016) Saliva as a diagnostic tool for oral and systemic diseases. J Oral Biol Craniofac Res 6: 66-75. Link: https://bit.ly/3yBsCVG

16. Nokes DJ, Enquselassie F, Nigatu W, Vyse AJ, Cohen BJ, et al. (2001) Has ora fluid the potential to replace serum for the evaluation of population immunity 
levels? A study of measles, rubella and hepatitis B in rural Ethiopia. Bull World Health Organ 79: 588-595. Link: https://bit.ly/2RHGJlr

17. Andries AC, Duong V, Ly S, Cappelle J, Kim KS, et al. (2015) Value of routine dengue diagnostic tests in urine and saliva specimens. PLoS Negl Trop Dis 9: e0004100. Link: https://bit.ly/3feQeYB

18. Barskey AE, Schulte $C$, Rosen JB, Handschur EF, Rausch-Phung E, et al. (2012) Mumps outbreak in Orthodox Jewish communities in the United States. N Eng J Med 367: 1704-1713. Link: https://bit.ly/2SjBvTh

19. Wellington K, Goa KL (2003) Measles, mumps, rubella vaccine (Priorix; GSK MMR): a review of its use in the prevention of measles, mumps and rubella. Drugs 63: 2107-2026. Link: https://bit.ly/3bOFduV

20. Plotkin SA (2004) Mumps vaccine. In: Plotkin SA, Orenstein W, Offit P, editors. Vaccines. Philadelphia: Saunders 441-469. Link:
21. Moussallem TM, Guedes F, Fernandes ER, Pagliari C, Lancellotti CL, et al. (2007) Lung involvement in childhood measles: severe immune dysfunction revealed by quantitative immunohistochemistry. Hum Pathol 38: 1239-1247. Link: https://bit.ly/2QIH8Kg

22. McLean HQ, Fiebelkorn AP, Temte JL, Wallace GS (2013) Prevention of measles, rubella, congenital rubella syndrome, and mumps, 2013: summary recommendations of the Advisory Committee on Immunization Practices (ACIP). MMWR Recomm Rep 62: 1-34. Link: https://bit.ly/2QL5ymp

23. Liu Y, Liu Z, Deng X, Hu Y, Wang Z, et al. (2018) Waning immunity of one-dose measles-mumps-rubella vaccine to mumps in children from kindergarten to early school age: a prospective study. Expert Rev Vaccines 17: 445-452. Link: https://bit.ly/347xpAq

24. Beleni Al, Borgmann S (2018) Mumps in the Vaccination Age: Global Epidemiology and the Situation in Germany. Int $\mathrm{J}$ Environ Res Public Health 15: 1618. Link: https://bit.ly/3fJIM6Q

\section{Discover a bigger Impact and Visibility of your article publication with}

\section{Peertechz Publications}

\section{Highlights}

* Signatory publisher of ORCID

* Signatory Publisher of DORA (San Francisco Declaration on Research Assessment)

* Articles archived in worlds' renowned service providers such as Portico, CNKI, AGRIS, TDNet, Base (Bielefeld University Library), CrossRef, Scilit, J-Gate etc.

* Journals indexed in ICMJE, SHERPA/ROMEO, Google Scholar etc.

* OAI-PMH (Open Archives Initiative Protocol for Metadata Harvesting)

* Dedicated Editorial Board for every journal

* Accurate and rapid peer-review process

* Increased citations of published articles through promotions

* Reduced timeline for article publication

Submit your articles and experience a new surge in publication services (https://www.peertechz.com/submission).

Peertechz journals wishes everlasting success in your every endeavours.

Copyright: (C) 2021 Carvalho Sampaio BF, et al. This is an open-access article distributed under the terms of the Creative Commons Attribution License, which permits unrestricted use, distribution, and reproduction in any medium, provided the original author and source are credited. 